\title{
Exploring Beninese Preservice Efl Teachers' Perspectives on the Features of the Ideal Efl Teacher
}

\author{
Jean-Marc Gnonlonfoun* \\ GRI-DiGeST/LARPET/ENSET/UNSTIM-A
}

\section{*Corresponding Author}

Jean-Marc Gnonlonfoun

\section{Article History}

Received: 21.05.2020

Accepted: 02.06 .2020

Published: 07.06.2020

\begin{abstract}
The stated purpose of this study was to know the competency profile of the ideal EFL teachers as viewed by preservice EFL teachers through the identification and description of the qualities that these preservice students attribute to excellent teachers. In this view, the biographical-narrative approach was adopted. 120 preservice EFL teacher students from the Ecole Normale Supérieure de Porto-Novo were onsidered with an effective participation rate of 88, $33 \%$. The findings indicated that personal qualities are fundamental in the definition of the profile of the competent teacher. Therefore, it is expected that these profiles be taken into account to design training curricula that favor the wholistic development of teachers.
\end{abstract}

Keywords: Competent teacher, EFL preservice teachers' views, personal and professional skills and abilities, Benin context.

\section{Problem and Purpose}

It is evident that if the centrality of the figure of the student in the design of an open and flexible curriculum is defended, teachers should investigate with a reflective and critical spirit to find guidelines that help us strengthen and to prop up each stage of the teaching-learning process in the most convenient way. Without a doubt, this conviction inevitably leads to rethink the figure of the teacher in a scenario characterized by the dynamics of technological, social and cultural changes in which we are immersed.

Assuming this general starting point, this research reflects on the figure of the ideal teacher of foreign languages, establishing a comparison of profiles. This work intends to collect data to know the competency profile of a good teacher, by identifying and describing the qualities that preservice students attribute to excellent teachers.

In other words, the general objective of the study carried out has been to know the meanings that they elaborate, the beliefs, the points of view or the attitudes that the preservice EFL students have in relation to the figure of the competent teacher. The specific objectives in which this general objective is specified are the following:

i. To identify the representations built by preservice EFL teacherstudents around the figure of the ideal teacher.

ii. To analyze and describe the beliefs perceived by these preservice EFL teacherstudents in the configuration of teaching excellence related to three areas: training (knowing), acting (knowing how to do) and attitudes (knowing how to be).

iii. To order and classify the qualities that determine the profile of the EFL teacher that preservice EFL teacherstudents attribute to the most competent teachers.

iv. To compare some results with those in the literature.

The biographical-narrative approach adopted allows broadening the knowledge on the point of view of those involved, starting from two data collection instruments: an open report (in the first phase of the investigation) and the final report (in the second phase). In the first phase of the study, the researcher has taken advantage of the epistemic

Copyright @ 2020: This is an open-access article distributed under the terms of the Creative Commons Attribution license which permits unrestricted use, distribution, and reproduction in any medium for non commercial use (NonCommercial, or CC-BY-NC) provided the original author and source are credited. 
function that, without a doubt, offers the analysis of the representations built on the figure of the ideal teacher, to study how they are interpreted and reconstructed by the preservice EFL students. Likewise, a brief comparison is to be established between the ideal profile defined by the participants in this our research and the profile derived from the literature.

\section{Examining the literature}

Before addressing the analysis of the representations on which the profile of the ideal teacher is configured based on the characteristics that identify him, one should ask himself how a teacher constructs his professional identity. Obviously, the answer will be complex, but surely it will be linked to the reflection on the own representations (conceptions and beliefs) generated from an individual exercise of introspection, reflection and analysis. As is known, representations act as a filter to all cognitive input and constitute the fundamental scaffolding to memorize, classify, process and interpret information. These representations also constitute the base on which teaching practice is taught, so any teaching-learning approach that claims the centrality of the figure of the student will need to be informed about the representations of the students themselves. And the study of the representations of preservice EFL teachers (teacherstudents) seems especially relevant since they are faced with the challenge of developing practical knowledge that will require them to "learn to teach", which implies, among other things, exercising reflection on oneself, (self) observation and making judgments. In addition to factors of a socio-professional nature, individual biographical processes and personal development trajectories, the challenge of this stage of "life transition" will have a significant impact on their own identity as a teacher, because, as Giddens affirms [1], the construction of identity begins to be defined in the course of the initial formation process, in the construction of a body of knowledge and know-how and of the internalization of that knowledge in knowing how to be, which identifies the teacher as a person constructed by a multiplicity of life experiences.

For Dubar [2], identity is the result, stable and provisional, individual and collective, subjective and objective, biographical and structural, of a variety of socialization processes that jointly construct individuals and characterize institutions. Expectations, values and norms are also part of the same unitary process of identity formation. Representations or beliefs become a way of interpreting and thinking about everyday reality because they provide us with the conceptual tools that teachers apply in our methodological practice. They are as much the result of the construction of subjectivity as of social experience. Indeed, we move with our beliefs, we live in them and we are them.

\section{MeTHODOLOGY}

The mental representations have a constructive character because the subjects are part of social groups and elements are introduced into their construction process that transcends the individual. Gómez [3] affirms that representations are not transmitted, but are cognitive constructions that are carried out within a social group. In her views, the individual builds his knowledge in social settings and during cultural practices. In these practices, the knowledge already elaborated by the group is not received, what the individual does is elaborate the knowledge by himself, from patterns of experiences obtained in his psychosocial environment. The individual synthesis of knowledge is fostered by the practices and network of interpersonal relationships that constitute the manifestation of culture. This is how it is assumed that the individual is an active constructor of knowledge but that requires an experiential and interpersonal framework.

In the representations, a cognitive and symbolic elaboration process takes place to channel behaviors. Precisely deepening this relationship of symbolic processes with behaviors has led to design the research because making representations explicit leads to questioning and can generate transformations by becoming a way of thinking and interpreting reality that are analyzed.

\section{Foundation}

The researcher has ensured that the components of this study are related to the ontological, epistemological and methodological aspects that underpin qualitative research, given the uncertainty and complex nature of socio-educational research as a social construction. From the epistemological perspective, therefore, it is assumed that an inductive path that starts from the analysis of the data provided by the narrative records of participants to arrive at a later theorization.

From the methodological point of view, the design of this research has an emergent character, since it has been built as the process of analysis of how the different visions and perspectives of the participants have progressed. Regarding the instruments and strategies for collecting information, we have used techniques that allow us to collect data that make possible an exhaustive description of the concrete reality under investigation, based on the informants' discursive reasoning process. 


\section{Participants}

The sample involved in the study consisted of 120 preservice EFL teacher students from the Teacher Training School of Porto-Novo (Ecole Normale Supérieure de Porto-Novo) who completed either a BAPES (Brevet d'Aptitude au Professorat de l'Enseignement Secondaire) or a CAPES (Certificat d'Aptitude au Professorat de l'Enseignement Secondaire) in during the 2016-2017 and 2017-2018 academic years.

Of the 120 targeted and contacted, 106 effectively took part in the study, giving an agreement rate of $88 \%$ which is acceptable. Of these 72 were women and 34 men, aged between 25 and 43 years, with an average age of 25 years.

\section{Procedures used for the collection and analysis of data}

For the processing and analysis of the information, the representations of the 106 participants were taken, applying as an information collection strategy an instrument based on an indirect and non-interactive technique: documentary analysis.

Participants were asked an open, descriptive, non-directive question that allowed them to capture their point of view without interference and to account for the way in which they conceive and assign content to the notion of ideal teacher. This is precisely the significance and reliability of the information, because it is the informants themselves who introduce their priorities.

The question asked as an object of discourse analysis was the following: In your opinion, what qualities do you think constitute the profile of the ideal EFL teacher? Present the main features and briefly describe them. Their written production was collected before the period of external internships began.

With all the information collected, the researcher proceeded to analyze and reduce the data through a systematic, ordered, but necessarily flexible process of categorization and coding, since by segmenting them into units of meaning, we realized that the categories were tentative, and not the result of a mechanical process, but of what some have called "intellectual craftsmanship". The process emphasized the construction and inductive generation of categories to be able to classify the collected data. Therefore, it was not linear, but was being built and remained open to changes and redefinitions. The researcher hypothesizes that the hermeneutic work that characterizes qualitative studies and, therefore, to give meaning to the reality that was being investigated and to structure the profile of the ideal teacher based on the characteristics that we were collecting. A triple dimension was established: formative, technical and, finally, ethical and affective-motivational. These three dimensions have permeable borders that interpenetrate each other, influence each other and together collaborate in the construction of the so-called teaching competence.

\section{FINDINGS}

The results of the analysis offer a conception of teaching as a multidirectional communicative process that addresses the development of abilities and skills that can be classified into three areas: training, classroom practices (performance) and attitudes, values and emotional factors.

\section{The Training Dimension}

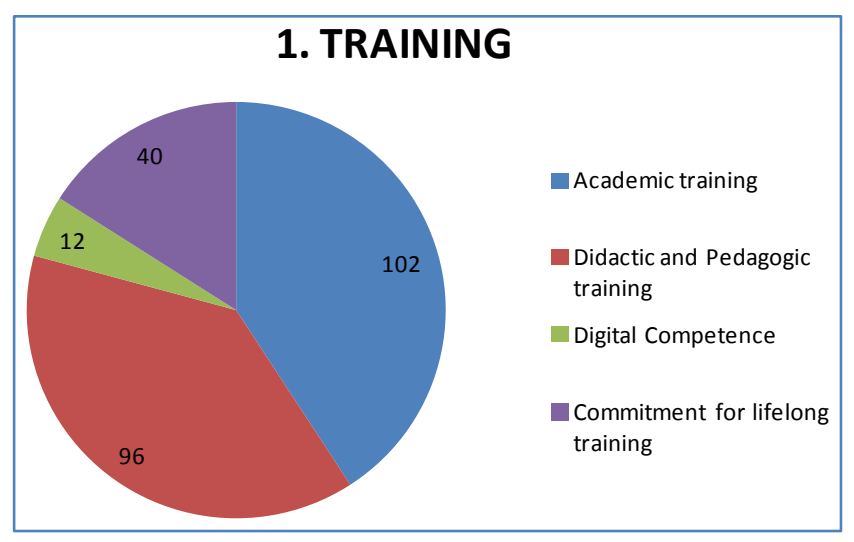

In reference to the above figure related to the training dimension, it appears that almost all the participants refer to the need for a balance between rigorous training in the technical content related to the subject being taught (102) and training in the domain of pedagogical resources (96). Likewise, the competent teacher is characterized by his capacity for updating, renovating and recycling (40). He cannot count only on his experiential baggage to build and develop his theories on teaching and learning. It is surprising that only 12 participants have pointed out the importance of digital 
teaching competence, since it constitutes one of the areas of teacher professionalization that is least well attended in initial training; despite the fact thatit facilitates a more effective, motivating and inclusive learning.

\section{Classroom Practices}

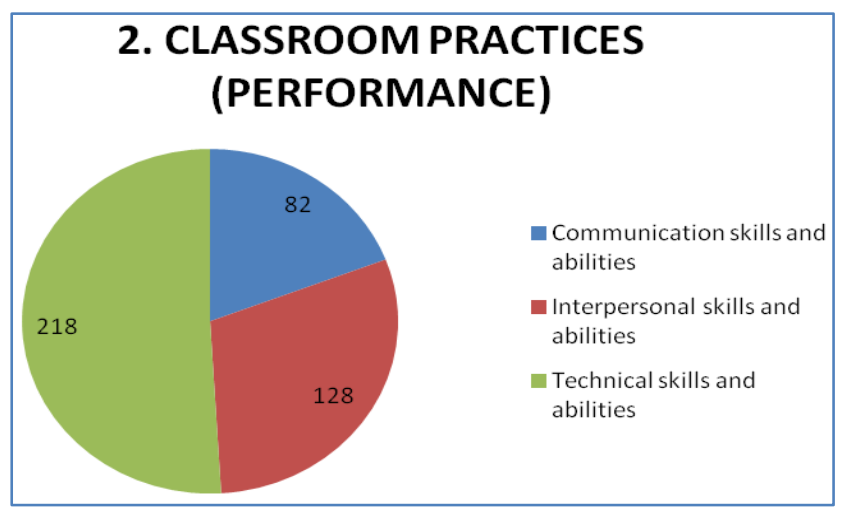

In this sub-section, the data referring to the technical dimension are synthesized. This has been done according to the type of skills and abilities to which they are linked: communication, interpersonal and organization and management of the teaching-learning process.

i. Communication skills and abilities

Very often noted features include adjectives, words, expressions and comments such as:

- dynamic, enthusiastic, active, passionate, jovial,

- good communicator,

- $\quad$ importance of non-verbal language and parallel language, not pedantic, actor,

- Once the teacher enters the class, the students do not realize if he has a bad day, is ill, is in a hurry or has had little time to prepare the class.

ii. Interpersonal skills and abilities

Very often noted features include adjectives, words, expressions and comments such as:

- He promotes group interaction and encourages participation,

- He offers positive feedback,

- He has the ability to listen,

- He accepts the group's proposals,

- He comments on the learning process of the students,

- He knows the name of the students,

- He promotes the critical opinion of the student,

- You must leave room for students to participate,

- He allows students to communicate with each other without continually attracting attention,

- Ability to work in a team,

- Ability to adapt.

iii. Technical skills and abilities

\section{Planning}

Very often noted features include adjectives, words, expressions and comments such as:

- He plans the classes, He is organized and methodical.

- This does not prevent, however, that the teacher must have the ability to improvise to modify the course of the class if the situation requires it.

- He is flexible.

- He must have sufficient capacity to adapt to different situations in which it may occur in the classroom. This means that it is necessary to find a compromise between being methodical and flexible.

\section{- Goals}

Very often noted features include adjectives, words, expressions and comments such as:

- He promotes significant learning.

- He explains the reasons and learning goals of classroom work. 


\section{- Methodology}

Very often noted features include adjectives, words, expressions and comments such as:

- He justifies the methodology used and comments on the progress made.

- The students are aware of the progress or failures of their learning process.

\section{- Students' needs and interests}

Very often noted features include adjectives, words, expressions and comments such as:

- He knows how to identify the needs and interests of students.

\section{- Activities and materials}

Very often noted features include adjectives, words, expressions and comments such as:

- He uses creative teaching material, with varied and useful activities.

- He uses current teaching material and according to the tastes and interests of the learners.

- He develops individual and group activities.

\section{- Error handling}

Very often noted features include adjectives, words, expressions and comments such as:

- He corrects properly.

- He issues positive evaluations, based on what the student does well, reinforcing and valuing it. In the same way, it presents what it does not do so well in terms of improvement.

- He corrects errors constructively and considers them as a step that is part of the language learning process.

- He knows how, when and what errors to correct.

\section{- Evaluation}

Very often noted features include adjectives, words, expressions and comments such as:

- He is a good evaluator.

- $\quad$ He is consistent with his methodology, effective in design and just when correcting, also providing useful and adequate feedback.

- He proposes self-evaluation.

- He knows the limitations of his students.

- He is versatile.

- It is essential that a good teacher is able to adapt to the environment, both to the work environment of the institution where he is, and to the characteristics of the site and the specific needs of his students.

- He takes into account external factors to the classroom.

- He simplifies the complex by managing a gradual progression of reasonable difficulty.

- He meets the deadlines and sets standards and gives clear instructions.

- He follows a specific methodology.

\section{- Attitudes, values and motivation}

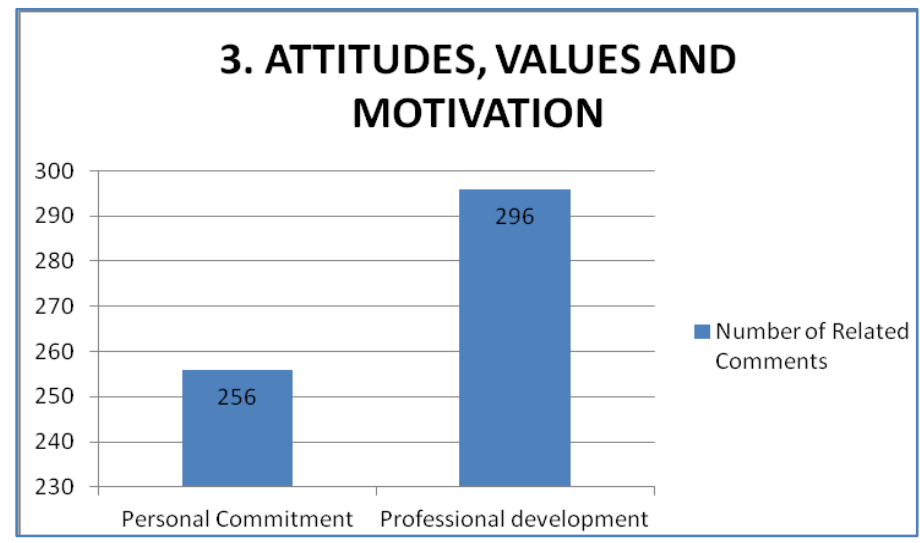

This section includes data related to the ethical and affective-motivational dimension, because the beliefs of participants about the ideal teacher do not only reflect characteristics related to their training or the pedagogical techniques they use to manage the classroom or improve processes teaching-learning, but also -and in a very relevant way- with the teacher as a person, and therefore, with his attitudes, values and emotional factors. 
- $\quad$ Attitudes, values and emotional factors linked to professional development

Very often noted features include adjectives, words, expressions and comments such as:

- He is creative, motivator, self-critical, innovative and motivated.

- He is passionate about what he does.

- $\quad$ His ability to resolve conflicts;

- $\quad$ He is demanding (but understanding)

- He is in charge with the preparation of the classes, the schedules, the correction of exercises and exams.

- He is aware of his role and work as an educator: for him, the classroom is a space where learners will acquire knowledge, but also to relate, to know new ways of thinking, of seeing the world, of learning ... It is a restructuring of their own thought. And in all this, the role of the teacher as an educator is extremely important.

- He shows interest. He is an integrator in that he must watch over each and every one of his students, making each of them an active part of the group.

- He knows how to manage the emotions and feelings of the group and make them eager to excel.

- He displays confidence and self-confidence and he is reflective and honest. He recognizes that everything can be improved and for this reason he uses criticism and his experiences in the classroom to be a better teacher; accepts constructive criticism well. If he does not know how to answer a question that a student asks or he is not sure, he says so.

- $\quad$ He is professional in that he tries to prevent his personal problems from affecting him when carrying out his work.

- $\quad$ He transmits interest and does not treat the student as a mere receptacle.

\section{- Attitudes, values and emotional factors of personal commitment}

Very often noted features include adjectives, words, expressions and comments such as:

- He is friendly and close, accessible and empathetic with a sense of humor.

- He is optimistic and enthusiastic. He is also open-minded and respect and listen to the opinions and doubts of the students.

- He transmits confidence and self-confidence. In addition he is impartial and treats everyone equally.

- He is also punctual with good presence.

\section{DISCUSSION}

The results obtained provide elements that allow contrasting, albeit in a very synthetic way, the emerging semantic map of the analysis carried out in this study with those obtained in the literature. The most prominent study from the literature is the report of a study carried out by the Cervantes Institute. In this study, the beliefs of the students, teachers and technical and managerial staff of the institution were analyzed. Based on the data collected in that report, the Cervantes Institute publishes in 2012 The Key Competences of Second and Foreign Language Teachers, which undoubtedly constitutes a framework for the coherent development of training actions aimed at these teachers. This has already been adopted as a benchmark in numerous institutions and educational centers both when defining the key competences of the modern foreign language teacher, as well as to focus their training and professional development.

The following is a comparative figure, which reflects the general aspects most valued by teachers and students. The low percentage (19\%) that teachers attribute to personal characteristics is striking, compared to $39.9 \%$ in student responses:

\section{General comparison between Teachers and Students'answers [4]}

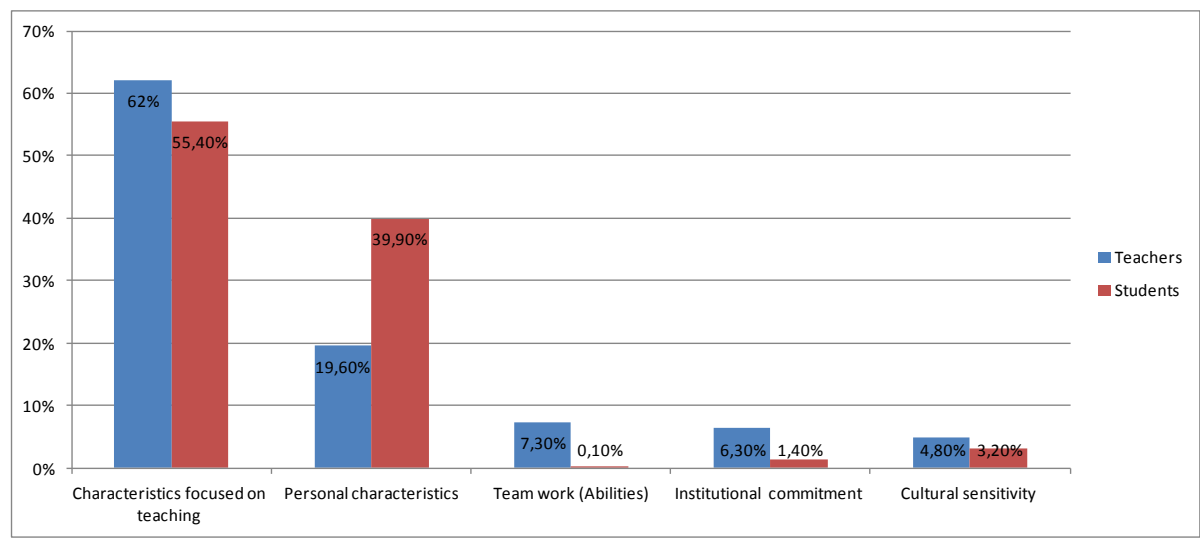


The sample of the present study was made up of preservice EFL students who were preparing to carry out their work practices as new teachers, that is, they were located in what could be called a "turning stage" between two identities in continuous construction: that of the student and that of the teacher. The literature also shows the relevance of the teacher's personal characteristics above the academic and professional competences that fall within the fields of training and action.

The results of the present study indicate several similarities that identify a corpus of capacities that define the competent teacher, very close to that offered by the Cervantes Institute. Within the category characteristics focused on teaching, the three aspects most valued by the students of this institution are that they have a good training, that they promote student-centered teaching and that they manage the learning process.

A large number of participants in this study noted that the most relevant communication skills and abilities in the field of performance are being dynamic, enthusiastic, active, jovial and a good communicator. In the same field, they indicated that the ideal teacher promotes group interaction and favors participation. Planning the classes is also indicated as one of the most important "technical" (organization and management) skills and abilities displayed by the ideal teacher in that he needs to be organized and methodical. The fourth characteristic most pointed out by participants knew how to identify the needs and interests of students.

For participants in the present study, the ideal teacher is any individual that shows in the field of attitudes, values and emotional factors the following features:

1) friendly and close, accessible (open, kind, pleasant);

2) empathetic;

3) motivating;

4) with a sense of humor;

5) tolerant;

6) optimistic and enthusiastic attitude;

7) respectful;

8) fosters interculturality and social values;

9) transmits confidence and self-confidence;

10) Aware of his work as an educator.

\section{CONCLUSION}

This research is an attempt to determine the profiles that emerge from the conceptions and expectations that preservice EFL students express in relation to the figure of the ideal teacher. However, it should not be forgotten that the teaching profession has an indisputable vocational character and that teachers face new needs and new demands every day that require a high degree of involvement and commitment. Thus, personal qualities are a fundamental aspect to define the profile of the competent teacher. That may be why participants to this study emphasize the need to weigh the characteristics linked to both attitude and aptitude for professional performance. Likewise, the analysis of beliefs about the competency profiles of the best teachers offer valuable guidelines for designing training curricula that favor the wholistic development of teachers.

\section{REFFERENCE}

1. Gewerc, A. (2001). "Professional identity and career in the university", teaching staff: Magazine of curriculum and teacher training, 5, 2, 31-46.

2. Dubar, C. (1991). La socialization: construction of social identities and professionals. Paris: Armand Colin.

3. Arbeláez Gómez, M.C. (2002). "The mental representations", Human Sciences, 29.

4. Instituto Cervantes. (2012). The key competences of teachers of second and foreign languages, from http://cvc.cervantes.es/ensenanza/biblioteca_ele/competencias/default.html 